\title{
AMELIORATING THE METABOLIC DISORDER IN STREPTOZOTOCIN-INDUCED DIABETIC RATS BY HAEMATOCOCCUS PLUVIALIS EXTRACT
}

\author{
FAROUK K EL-BAZ ${ }^{1 *}$, HANAN F ALY ${ }^{2}$ \\ ${ }^{1}$ Department of Plant Biochemistry, National Research Centre, Giza, Egypt. ${ }^{2}$ Department of Therapeutic Chemistry, National Research \\ Centre, Giza, Egypt. Email: elbazfk@gmail.com
}

Received: 15 February 2017, Revised and Accepted: 09 March 2017

\section{ABSTRACT}

Objective: The purpose of this study is to evaluate the antidiabetic influence of Haematococcus pluvialis ethanol extract on streptozotocin-induced rats.

Methods: This influence was assessed by measuring asymmetric dimethylarginine (ADMA), von Willebrand factor (vWf), 15-lipoxygenase (15-LOX), 5-LOX, epidermal growth factor (EGF), and lipoxin-A4 (LXA4). The histopathological examinations of cardiac and renal tissues were also performed.

Results: The presented results showed an elevation in the levels of ADMA, vWf, 15-LOX, and 5-LOX with percentages increase 430.30, 77.54, 61.05, and $81.09 \%$, respectively in diabetic rats. However, the EGF and LXA4 levels were decreased significantly (44.17 and 51.94\%, respectively), compared to normal control rats. On the other hand, treatment of diabetic rats with H. pluvialis improved ADMA, vWf, 15-LOX, 5-LOX, EGF, and LXA4 levels with amelioration percentages; $269.69,54.77,55.78,72.68,53.39$, and 56.58\%, respectively. In addition, the histopathological examination of cardiac tissue in diabetic rats revealed congestion of myocardial blood vessel, vacuolation of the sarcoplasm of cardiac myocytes and focal necrosis of myocytes associated with inflammatory cells infiltration. Beside, vacuolation of the epithelial lining of renal tubules and endothelial lining glomerular tuft as well as cystic dilatation of renal tubules was detected. However, cardiac tissue and renal tubules of diabetic rats treated with $H$. pluvialis ethanol extract $(150 \mathrm{mg} / \mathrm{kg}$ b.wt.) showed normal cardiac myocytes, vacuolation of epithelial lining renal tubules and endothelial lining glomerular tuft, congestion of glomerular tuft and intertubular renal blood vessels.

Conclusion: These results confirmed the improving role of H. pluvialis in controlling type 2 diabetes.

Keywords: Haematococcus pluvialis, Streptozotocin, Type 2 diabetes, Asymmetric dimethylarginine, Von Willebrand factor, Lipoxygenases, Histopathological examination.

(c) 2017 The Authors. Published by Innovare Academic Sciences Pvt Ltd. This is an open access article under the CC BY license (http://creativecommons. org/licenses/by/4. 0/) DOI: http://dx.doi.org/10.22159/ajpcr.2017.v10i6.17785

\section{INTRODUCTION}

Diabetes mellitus (DM) is a group of metabolic disorders of the endocrine system mainly divided into two types; type 1 DM (T1DM) and type 2 DM (T2DM) which characterized with hyperglycemia (high blood glucose level). T2DM represents the majority of diabetes conditions over the world, therefore; it is needed to find an economically and therapeutically effective treatment for usage in developing and under-developed countries [1]. The elevated levels of asymmetric dimethylarginine (ADMA) inhibit NO synthesis and therefore impair endothelial function and thus promote atherosclerosis and cardiovascular disorder [2] as well as in type 2 diabetic patients with retinopathy [3]. Furthermore, ADMA is linked to the development of renal disease where, elevated levels of ADMA have been described [3], due to, ADMA is directly related to blood glucose levels [4].

With respect to epidermal growth factor (EGF), it is considered as an important biomarker in the restoration, mechanism, expressible on fibroblasts, epithelial cells, and promotes recovery of the damaged epithelium. In diabetic mice, these repaired cells can ameliorate flow of blood by elevating the rate of consistence of novel vessel, which also helps in the healing process [5]. It maintains the process of healing of oral and gastroesophageal ulcers through stimulation of DNA synthesis, cell migration and proliferation [6]. Moreover, EGF regulates the major function of the pancreas insulin secretion; it stimulates the secretion of insulin in a pancreatic beta-cell of mice [6]. In addition, EGF elevated the level of insulin so intercede the lowering of glucose in plasma of normal mice and diabetic one [6]. Hence, EGF is a new product that adjusts the levels of glucose in plasma and it regards as a choice for a therapeutic progress of diabetes [5].
Dynamically, the inflammatory process is a controlled procedures ranged by interfaces which perform critical adjusting function such as cytokines, chemokines, and lipid mediators; the lipoxins (LXs), resolvins, and protectins [7]. Moreover, human lipoxygenases (LOX) and their metabolites have been involved in several diseases including allergic rhinitis, cancer, asthma, allergy atherosclerosis, and diabetes [8]. Regarding to von Willebrand factor (vWf), it is endothelial cells synthesizing glycoprotein, implicated in adhesion and accumulation of platelet besides it is coagulation factor VIII carrier in plasma [9]. Further, the elevated vWF levels were connected with cardiovascular disease (CVD) risk in patients with T2DM or resistance of insulin, proposing that $\mathrm{vWF}$ is a critical marker unique to these disorders [9].

The rapiers used in diabetes have limited efficacy or side effects such as hypoglycemia, body weight gain, flatulence, and gastrointestinal disorders [10]. Unusual marine environments are attributed to different bioactive compounds that make marine organisms' important source of biologically active substances using in therapeutics progress [11]. Chlorophyte alga Haematococcus pluvialis is the highest known source of astaxanthin (ASTA) in nature [12]. Where, ASTA content in H. pluvialis may exceed $4 \%$ of dry weight that is considered the highest content reported for any microorganism such as bacteria, fungi, and other microalgae [13]. Thus, H. pluvialis had a great interest for the commercial production of ASTA high value [14]. The basic and clinical research on ASTA health benefits have rapidly developed due to it has a preventive effect against oxidative stress-related diseases [15]. Moreover, ASTA has a considerable potential in the prohibition and handling of different diseases including cancer, asthma, metabolic syndrome, rheumatoid arthritis, gastrointestinal, hepatic, and neurodegenerative diseases [16]. 
The aim of this study is to investigate the potential of $H$. pluvialis extract to ameliorate the metabolic disorder in streptozotocin (STZ)-induced diabetic rats.

\section{MATERIALS AND METHODS}

\section{Chemicals}

STZ was purchased from Sigma-Aldrich, India. All chemicals in this study were of analytical grade, products of Sigma, Merck and Aldrich. All kits were the products of Biosystems (Alcobendas, Madrid, Spain), Sigma Chemical Company (St. Louis, MO, USA), Biodiagnostic Company (Cairo, Egypt).

\section{H. pluvialis cultivation}

H. pluvialis (strain No. CCAP 34/7) was isolated by spreading $0.1 \mathrm{ml}$ of water samples collected from Nile River phytoplankton using BG11 media for algal isolation [17] into petri dishes containing $1.5 \%$ agar for solidification. Then, single colonies of algae were recultivated in the specified liquid media as non-axenic batch cultures (50 ml) at $25 \pm 2^{\circ} \mathrm{C}$ and $24 \mathrm{hrs}$ with continuous white fluorescent lamp intensity $\approx 2500$ Lux. Cultivation was carried out on an open pond with a capacity of $70 \mathrm{~L}$ containing $55 \mathrm{~L}$ of growth media. After cultivation, the biomass was initially separated from the water by gravitational settling and then further concentrated by centrifugation [18], then dried at $40^{\circ} \mathrm{C}$

\section{Preparation of ethanol extract}

$100 \mathrm{~g}$ of the algal powder was macerated in ethanol (80\%) and shacked on shaker (Heidolph UNIMAX 2010) for $48 \mathrm{hrs}$ at $150 \mathrm{rpm}$. The extract was filtered using a Buchner funnel and Whatman No. 4 filter paper, and the algal residue was re-extracted with the addition of fresh ethanol for another 2 times [19]. Combined filtrates were concentrated using Rotavapor (Heidolph-Germany) at a temperature of $40^{\circ} \mathrm{C}$ under vacuum to dryness. The evaporated extract so obtained was preserved at $-20^{\circ} \mathrm{C}$ in a freeze and kept until further use.

\section{Animals}

About fifty male Wistar rats (180-200 g) raised in the Central Animal House, National Research Centre (NRC) were used. Animals were acclimatized to the laboratory conditions at room temperature before the experimentation. Animals were kept under standard conditions of a $12 \mathrm{hrs} \mathrm{light/dark} \mathrm{cycle} \mathrm{with} \mathrm{food} \mathrm{and} \mathrm{water} \mathrm{in} \mathrm{plastic} \mathrm{cages} \mathrm{with}$ soft bedding. Before testing for blood glucose level or injection of STZ to induce diabetes, the rats were fasted overnight (at least $12 \mathrm{hrs}$ ) but had free access to water. The study was approved by the NRC Animal Ethical Committee Guidelines (approval no: 0111457) for the use and care of animals.

\section{Diabetes induction and animals' treatment}

STZ was dissolved in $0.01 \mathrm{M}$ citrate buffer immediately before use and induced by intraperitoneal injection of a single dose ( $45 \mathrm{mg} / \mathrm{kg}$ b.wt.) through the dorsal vein of the rats' penis [20]. After STZ injection, rats had free access to food, water and were given $5 \%$ glucose solution to drink overnight to encounter hypoglycemic shock [21]. Fasted blood glucose levels were assessed 72 hrs after STZ injection as well as glycosuria to confirm the diabetic states. Rats were considered to be diabetic if glycosuria was present for three consecutive days [22]. Only rats with a fasting blood glucose level of $\geq 300 \mathrm{mg} / \mathrm{dl}$ and positive urine glucose were used in the experiment. The antidiabetic glibenclamide reference drug was orally administrated at a dose of $10 \mathrm{mg} / \mathrm{kg} \mathrm{b} . w \mathrm{t}$. daily for 30 days [23].

\section{Experimental study}

About fifty rats were randomly divided into 5 groups of 10 in each group. Group 1: Normal control. Group 2: Normal rats treated with H. pluvialis ethanolic extract (150 mg/Kg b.wt.) [24]. Group 3: Diabetic rats. Group 4: Diabetic rats orally treated with H. pluvialis ethanol extract $(150 \mathrm{mg} / \mathrm{Kg}$ b.wt.). Group 5: Diabetic rats orally administered antidiabetic glibenclamide reference drug $(10 \mathrm{mg} / \mathrm{kg}$ b.wt.) daily for 30 days.

\section{Blood and tissue sample measurements}

Rats were fasted overnight (12-14 hrs), anesthetized by diethyl ether and blood collected by puncture of the sublingual vein in clean and dry test tube, left 10 minutes to clot and centrifuged at $3000 \mathrm{rpm}$ for serum. The separated serum was used for biochemical analysis of ADMA, vWf, 15-LOX, 5-LOX, EGF, and LXA4.

\section{Analytical methods}

ADMA was determined in serum by ELIZA method according to Valtonen et al. [25] vWf was measured by a quantitative direct enzyme immunoassay according to Fischer et al. [26]. 15-LOX was determined in brain tissue by HPLC method according to Hoffman et al. [27]. 5-LOX was determined in brain tissue by colorimetric method according to Anthon and Barrett [28]. EGF was determined by Puchades et al. [29]. LXA4 invasion assay was performed using a method described previously by Elsinghorst [30].

\section{Calculations}

$$
\begin{aligned}
& \% \text { Change to control }=\frac{\text { Mean of control }- \text { Mean of treated }}{\text { Mean of control }} \times 100 \\
& \% \text { of improvement }=\frac{\text { Mean of disease }- \text { Mean of treated }}{\text { Mean of control }} \times 100
\end{aligned}
$$

\section{Histological examination}

After the sacrifice of rats, heart and kidney samples were dissected and extracted from animals. Heart and kidney tissues were fixed in $10 \%$ formalin for 1 week washed in running tap water for $24 \mathrm{hrs}$ and dehydrated in ascending series of ethanol (50-90\%), followed by absolute alcohol. The samples were cleared in xylene and immersed in a mixture of xylene and paraffin at $60^{\circ} \mathrm{C}$. The tissues were then transferred to pure paraffin wax of the melting point $58^{\circ} \mathrm{C}$ and then mounted in blocks and left at $4^{\circ} \mathrm{C}$. Serial sections of 5 microns thick were prepared and mounted on clean glass slides and left in the oven at $40^{\circ} \mathrm{C}$ to dryness. The slides were deparaffinized in xylene and then immersed in descending series of ethanol (90-50\%). The ordinary hematoxylin and eosin ( $\mathrm{H}$ and $\mathrm{E}$ ) stain was used to stain the slides [31].

\section{Statistical analysis}

All the values were expressed as mean \pm standard deviation. Statistical differences between the means of various groups were evaluated by one-way analysis of variance using the Statistical Package for the Social Sciences (SPSS) program, version 11 followed by Co-state program to compare significance between groups. p-values of 0.05 or less were considered to be significant.

\section{RESULTS}

Effect of $H$. pluvialis extract on ADMA, vWf, 15-LOX, 5-LOX, EGF, and LXA4 levels in the different groups under investigation

The results in Table 1 showed the effect of $H$. pluvialis extract on ADMA, vWf, 15-LOX, 5-LOX, EGF, and LXA4 levels in different groups where insignificant change in their levels was recorded in normal rats treated with H. pluvialis extract. While increase in ADMA, vWf, 15-LOX, and 5-LOX levels was detected in diabetic rats $(430.30,77.54,61.05$, and $81.09 \%$, respectively), compared to normal control one. However, the EGF and LXA4 levels decreased in diabetic rats with percentages 44.17 and $51.94 \%$, respectively. On the other hand, treatment of diabetic rats with H. pluvialis improved ADMA, vWf, 15-LOX, 5-LOX, EGF, and LXA4 levels with amelioration percentages $269.69,54.77,55.78,72.68,53.39$, and $56.58 \%$, respectively.

\section{Histopathological examination of cardiac tissue}

Microscopical examination of normal control heart revealed normal cardiac myocytes (Fig. 1). Meanwhile, the heart of diabetic rats showed vacuolation of the sarcoplasm of cardiac myocytes (Fig. 2a), congestion of myocardial blood vessels and focal necrosis of myocytes associated with inflammatory cells infiltration (Fig. 2b). Some examined sections from diabetic rats treated with $H$. pluvialis extract revealed 
Table 1: Influence of H. pluvialis extract on ADMA, vWf, 15-LOX, 5-LOX, EGF, and LXA4 levels

\begin{tabular}{|c|c|c|c|c|c|}
\hline Groups parameters & Control & Control+H.pluvialis & Diabetes & Diabetes $+H$. pluvialis & Diabetes+drug \\
\hline $\mathrm{ADMA}(\mu \mathrm{mol} / \mathrm{l})$ & $1.32 \pm 0.34^{\mathrm{a}}$ & $1.27 \pm 0.22^{\mathrm{a}}$ & $7.00 \pm 0.39^{b}$ & $3.44 \pm 0.21^{\mathrm{c}}$ & $4.00 \pm 0.26^{c}$ \\
\hline$\%$ Change & - & 3.78 & 430.30 & 160.60 & 203.03 \\
\hline$\%$ of improvement & - & - & - & 269.69 & 227.27 \\
\hline vWf (ng/l) & $50.50 \pm 10.70^{\mathrm{a}}$ & $50.00 \pm 7.59^{\mathrm{a}}$ & $89.66 \pm 4.78^{b}$ & $62.00 \pm 3.88^{c}$ & $69.90 \pm 7.16^{c}$ \\
\hline$\%$ Change & - & 0.99 & 77.54 & 22.77 & 38.41 \\
\hline$\%$ of improvement & - & - & - & 54.77 & 39.12 \\
\hline 15-LOX (U/l) & $9.50 \pm 0.99^{a}$ & $8.11 \pm 0.38^{\mathrm{a}}$ & $15.30 \pm 1.69^{b}$ & $10.00 \pm 0.56^{\mathrm{a}}$ & $9.11 \pm 0.89^{a}$ \\
\hline$\%$ of improvement & - & - & - & 55.78 & 65.15 \\
\hline 5-LOX (U/l) & $11.90 \pm 1.34^{\mathrm{a}}$ & $11.37 \pm 0.34^{\mathrm{a}}$ & $21.55 \pm 2.90^{\mathrm{b}}$ & $12.90 \pm 1.65^{\mathrm{a}}$ & $13.30 \pm 0.89^{c}$ \\
\hline$\%$ Change & - & 4.45 & 81.09 & 8.40 & 11.76 \\
\hline$\%$ of improvement & - & - & - & 72.68 & 69.32 \\
\hline $\mathrm{EGF}(\mathrm{pg} / \mathrm{ml})$ & $53.09 \pm 2.21^{\mathrm{a}}$ & $49.00 \pm 3.10^{\mathrm{a}}$ & $29.64 \pm 3.21^{\mathrm{b}}$ & $57.99 \pm 3.90^{\mathrm{a}}$ & $59.80 \pm 2.00^{c}$ \\
\hline$\%$ Change & - & 7.70 & 44.17 & 9.22 & 12.63 \\
\hline$\%$ of improvement & - & - & - & 53.39 & 56.80 \\
\hline$\%$ Change & - & 3.86 & 51.94 & 4.63 & 6.25 \\
\hline$\%$ of improvement & - & - & - & 56.58 & 45.69 \\
\hline
\end{tabular}

Data are expressed as mean \pm SD of 10 rats in each group. Statistical analysis is performed using SPSS computer program (one way ANOVA) coupled with Co-state computer program, where unshared letters are significant at $\mathrm{p} \leq 0.05, \mathrm{H}$. pluvialis: Haematococcus pluvialis, statistical analysis is performed using SPSS computer program (one way ANOVA) coupled with Co state computer program, where different letters (a,b,c) are significant at $\mathrm{p} \leq 0.05$. While, identical letters (a,b,c) are considered insignificant at $\mathrm{p} \leq 0.05$

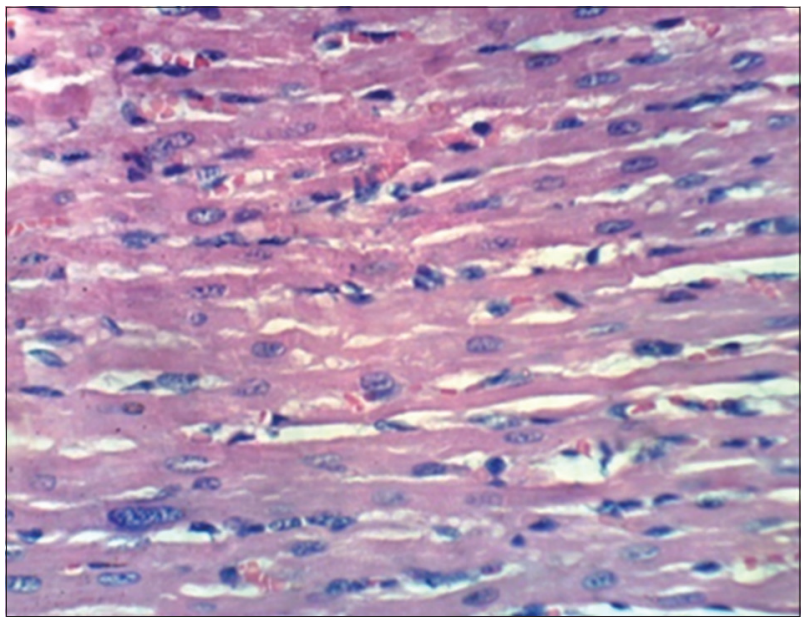

Fig. 1: Heart of normal control rats showing normal cardiac myocytes ( $\mathrm{H}$ and $\mathrm{E} \times 400)$

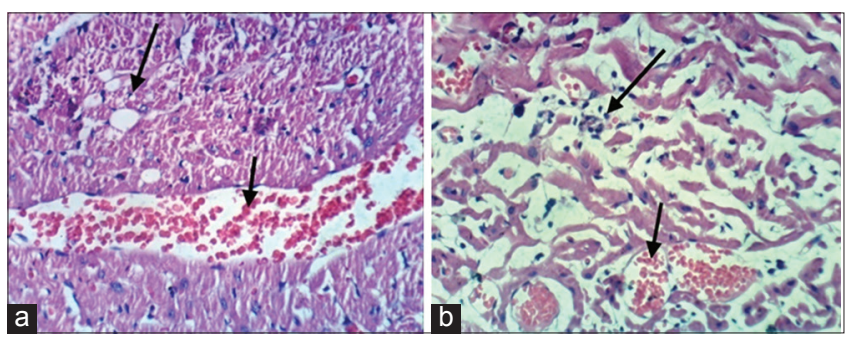

Fig. 2: (a) Heart of diabetic rats showing congestion of myocardial blood vessel and vacuolation of the sarcoplasm of cardiac myocytes (H and $\mathrm{E} \times 400$ ), (b) Heart of diabetic rats showing congestion of myocardial blood vessel and focal necrosis of myocytes associated with inflammatory cells infiltration $(\mathrm{H}$ and $\mathrm{E} \times 400)$

no histopathological changes with normal cardiac myocytes (Fig. 3). Moreover, marked improvement in the histopathological picture of diabetic rats heart-treated with glibenclamide drug (Fig. 4).

\section{Histopathological examination of renal tissue}

Microscopically, kidneys of rat from normal control group revealed the normal histological structure of renal parenchyma (Fig. 5). Meanwhile, diabetic rat kidneys showed vacuolation of epithelial lining renal tubules and endothelial lining glomerular tuft as well as cystic dilatation of renal tubules (Figs. 6a and b). Moreover, examined sections from the diabetic group treated with $H$. pluvialis extract revealed vacuolation of epithelial lining renal tubules, endothelial lining glomerular tuft, congestion of glomerular tuft, and intertubular renal blood vessels (Figs. 7a and b). However, improved picture was observed in kidneys of diabetic rats treated with glibenclamide drug, as the examined sections revealed renal tubules with vacuolation of the epithelial lining as well as glomerular tufts with slight congestion (Figs. 8a and b).

\section{DISCUSSION}

The current results revealed elevation in ADMA in STZ-induced diabetic rats. The increased levels of ADMA have been also detected in diabetic patients [32]. High blood glucose level was demonstrated to enhance ADMA levels by decreased its metabolism [32]. Clinical investigations in patients also indicated that ADMA is directly related to blood glucose levels [32]. Recently, intense regulation of blood glucose levels may extend antiatherogenic influences by lowering the levels of ADMA in T2DM patients [33]. It was suggested that, the high concentrations of ADMA are distinctly connected with the cases of coronary artery disease [34], T2DM [35], type 1 diabetes [36], and chronic heart failure [37]. ADMA is related also to the progression of diabetic complication such as renal disease incidence in patients with diabetic nephropathy [3] and T2DM patients with retinopathy [38]

Further, type 2 diabetes in these results is associated with the significant elevation in vWf. High vWF levels have been correlated well with the high risk of development of type 2 diabetes [39]. Beside, vWF has been linked with the insulin resistance in diabetic or nondiabetic cases [40]. In this context, Frankel et al. [9] revealed that vWf is inconsistently related to CVD and this may be attributed to the link of vWF with type 2 diabetes and insulin resistance. Dysfunction of endothelial cells is a systemic disease leading to atherosclerosis and CVD. Insulin resistance and diabetic status alleviated the connection between the high vWF and the increment in the CVD risk, pointing to vWF acts as a powerful moderator [9]. In addition, intense dysfunction of endothelial cells may be key atherogenic agents that responsible for the excess of 2-4 fold increase CVD risk observed in diabetes of type 2 [9].

The present results are also declared significant increase in 5 and 15-LOX levels in diabetic rats. 5-LOX has been implicated in cancer, asthma, allergic rhinitis, osteoarthritis, and atherosclerosis, whereas 15-LOX has been engaged in diabetic status, coagulation of blood, cancer 


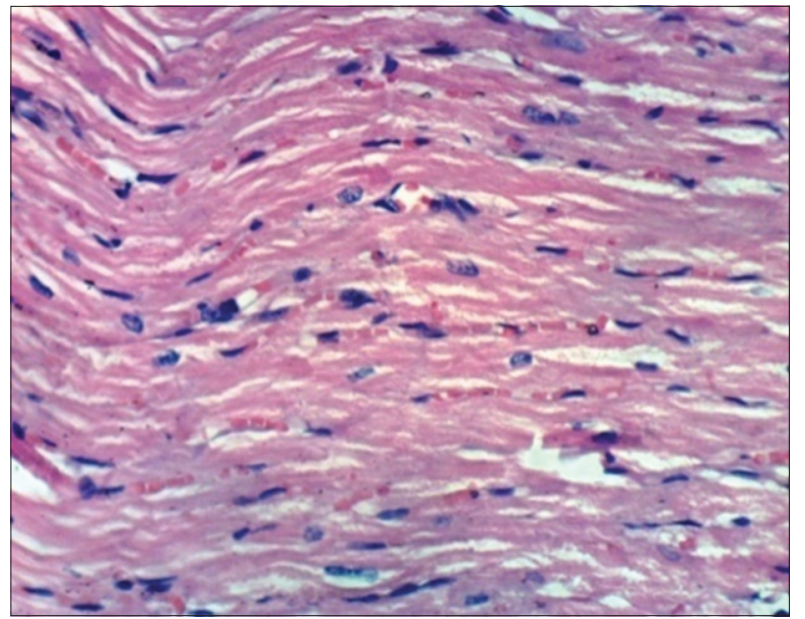

Fig. 3: Heart of diabetic rats treated with Haematococcus pluvialis extract showing normal cardiac myocytes $(\mathrm{H}$ and $\mathrm{E} \times 400)$

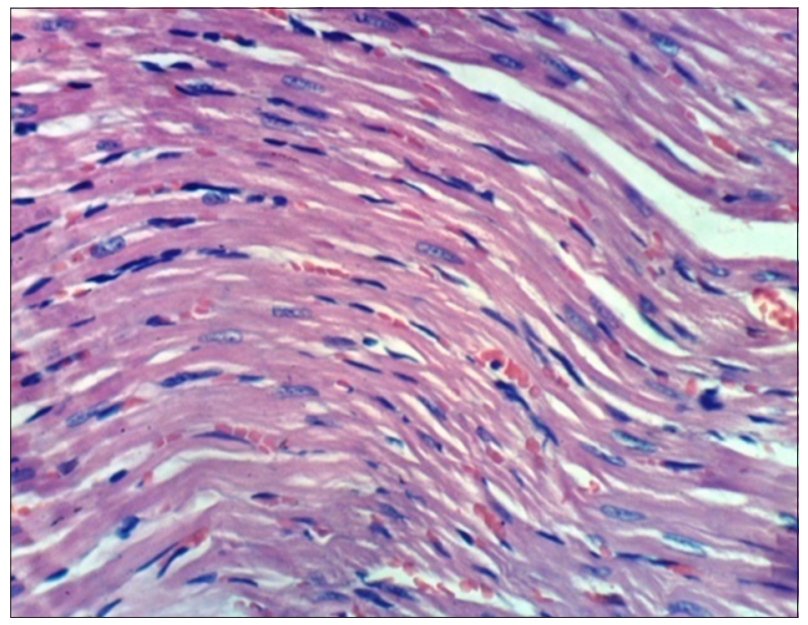

Fig. 4: Heart of diabetic rats treated with glibenclamide drug showing no histopathological changes $(\mathrm{H}$ and $\mathrm{E} \times 400)$

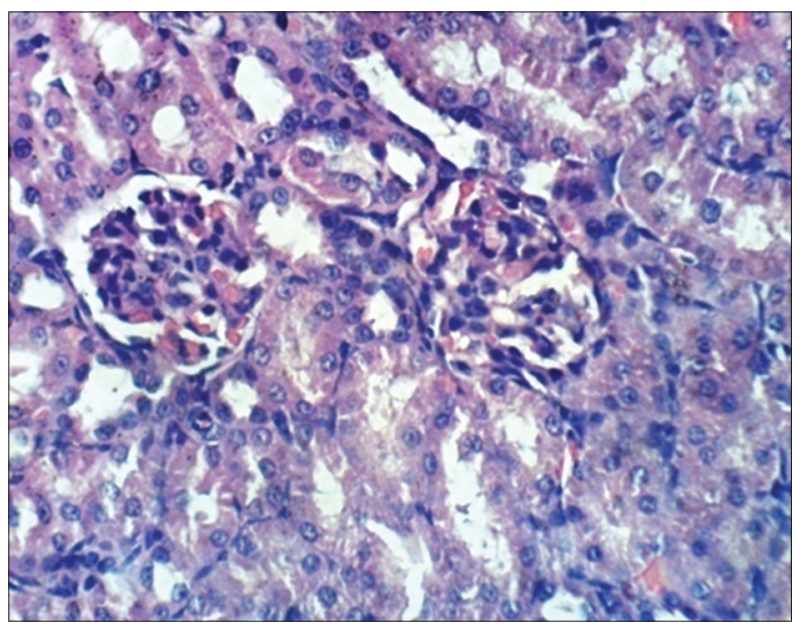

Fig. 5: Kidney of normal control rats showing the normal histological structure of renal parenchyma $(\mathrm{H}$ and $\mathrm{E} \times \mathbf{4 0 0})$

as well as psoriasis [8]. Human reticulocyte; 15- LOX-1 is regarded as an important curative goal, especially for its function in different disorders such as atherogenic and diabetic conditions, Alzheimer's disease, breast cancer, and stroke [8].

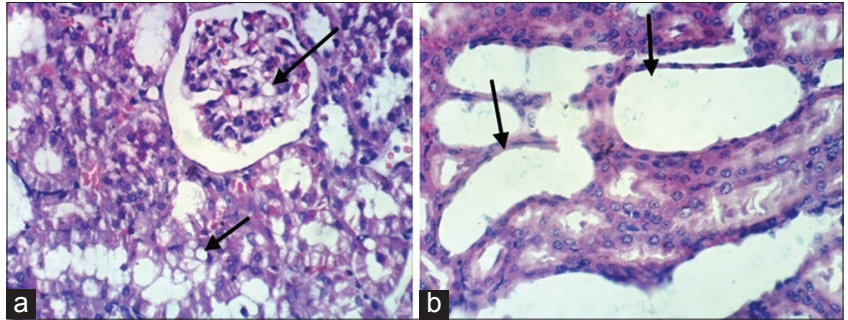

Fig. 6: (a) Kidney of diabetic rats showing vacuolation of epithelial lining renal tubules and endothelial lining glomerular tuft (H and $\mathrm{E} \times 400)$, (b) Kidney of diabetic rat showing cystic dilatation of renal tubules $(\mathrm{H}$ and $\mathrm{E} \times 400)$

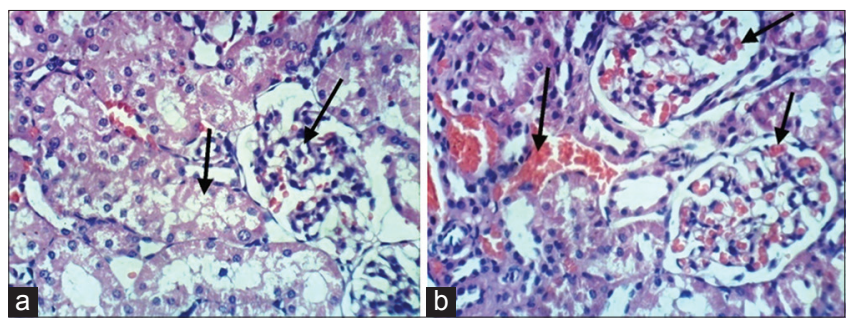

Fig. 7: (a) Kidney of diabetic rats treated with $H$. pluvialis extract showing vacuolation of epithelial lining renal tubules and endothelial lining glomerular tuft ( $\mathrm{H}$ and $\mathrm{E} \times \mathbf{4 0 0}$ ), (b) Kidney of diabetic rats treated with $\boldsymbol{H}$. pluvialis extract showing congestion of glomerular tuft and intertubular renal blood vessels ( $H$ and $E \times 400$ )

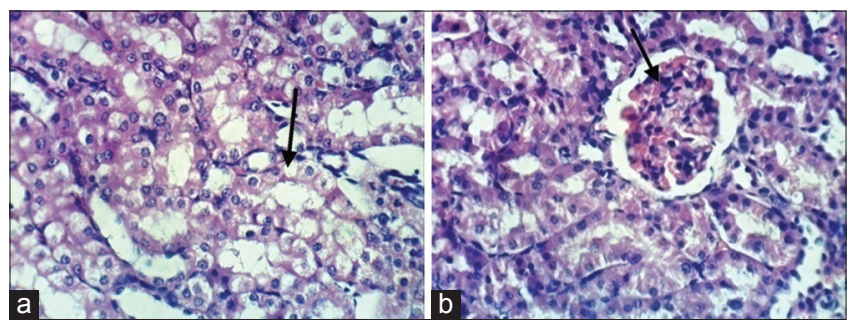

Fig. 8: (a) Kidney of diabetic rats treated with glibenclamide drug showing vacuolation of epithelial lining renal tubules

( $H$ and $\mathrm{E} \times 400$ ), (b) Kidney of diabetic rats treated with glibenclamide drug showing slight congestion of glomerular tuft ( $H$ and $E \times 400)$

Concerning EGF, the present results demonstrated significant decrease in EGF in diabetic rats. Al-Ankily et al. [5] explained that STZ-induced diabetes affects the binding of 125-labeled EGF to hepatic membranes negatively. Scatchard statistics demonstrated that the reduction in the binding of EGF was related to a lower in the receptors number. These findings evidenced that, insulin deficiency is a principle cause for the reduction in hepatic EGF receptors [41]. Further, in diabetic condition, plasma, submandibular gland EGF levels as well as the granular convoluted tubules size, which manufacture EGF, were noticed to be significantly reduced [41].

Considering LXA4, the current results showed significant reduction in LXA4 level in STZ-induced type 2 diabetes. It was found that IL-4 cytokine promoted anti-inflammatory action by enhancing LXA4 formation. The general purpose of LXs are to inhibit the proinflammatory prostaglandins, thromboxanes, isoprostanes and leukotrienes output, beside it, stimulates wound healing and dissolve inflammatory process hence, it repair tissues as well as the function of organs to normal. Hence, when the LXs synthesis is disturbed as in this findings, it could drive to a continual inflammation and hence tissue injury [24]. It was evidenced that the synthesis of LXs are 
reduced on $\beta$ cells of the pancreas and subjected to toxic agents such as IL-6, TNF-a, and migration inhibitory factor (MIF), which could lead to $\beta$-cell dysfunction or destruction and the onset of diabetes [42]. Thus, polyunsaturated fatty acids (PUFAs) and their anti-inflammatory molecules as LXs, suppress the output of different pro-inflammatory mediators included MIF and High-mobility group box 1 protein. Hence, they inhibit inflammation in various disorders as diabetes [42].

Accumulating evidence suggested that ASTA of $H$. pluvialis could do cardiac-preventative effects by ameliorating oxidative damage, inflammatory process, lipid, and glucose metabolism, hence improved architectures of cardiac and renal tissues as indicated in the present results. ASTA may also prevent diabetic nephropathy development by decrease renal oxidative stress and renal cell damage in $\mathrm{db} / \mathrm{db}$ mice [43]. ASTA is commonly isomers mixture synthesized by $H$. pluvialis microalga and is used as a supplement in nutrition, as an antioxidant, it captures free radicals, prevents peroxidation of the lipid membrane bilayer [11]. Further, its property as antioxidant is 10 -fold higher than other carotenoids, as lutein, canthaxanthin, and $\beta$-carotene [11]. In parallel, a recent meta-analysis showed that ASTA supplementation can lower glucose levels [15]. ASTA was found to be more efficient than vitamin E, it preserves rat liver mitochondria against lipid peroxidation [44]. It can induce xenobiotic metabolizing enzymes in the lung and kidney [45].

\section{CONCLUSION}

It could be concluded that diabetic complications are associated with metabolic disorders in the different organs including cardiac and renal tissues. However, normalization in this metabolic dysfunction is documented on using $H$. pluvialis extract related to its ASTA content. Further, clinical investigations are needed to use $H$. pluvialis as a promising candidate nutraceutical for ameliorating diabetic complications.

\section{ACKNOWLEDGMENT}

This work was supported and funded by the project entitled "Biodiesel production from algae as a renewable energy source". Funding organization: Research Development and Innovation program (RDI), Funding Program: EU-Egypt Innovation Fund, 2014-2017.

\section{REFERENCES}

1. Priyanka K, Singh R. A systematic review on Indian floral biodiversity as eminent reserves for alternative treatment strategy of diabetes mellitus. Int J Pharm Pharm Sci 2016;8(4):10-9.

2. Saleh DO, El-Awdan SA, Nofel SM, El-Eraky WI, El-Khatib AS, Kenawy SA. Estrogens improve the cardiovascular alterations in fructose-induced insulin resistant ovariactoized rats. Int J Pharm Pharm Sci 2015;7:241-7.

3. Ueda S, Yamagishi S, Matsumoto Y, Fukami K, Okuda S. Asymmetric dimethyl arginine (ADMA) is a novel emerging risk factor for cardiovascular disease and the development of renal injury in chronic kidney disease. Clin Exp Nephrol 2007;11:115-21.

4. Abbasi F, Asagmi T, Cooke JP, Lamendola C, McLaughlin T, Reaven GM, et al. Plasma concentrations of asymmetric dimethylarginine are increased in patients with Type 2 diabetes mellitus. Am J Cardiol 2001;88(10):1201-3.

5. Al-Ankily MM, Shamel M, Bakr MM. Epidermal growth factor and diabetes mellitus; friends or faux? Int J Med Dent Sci 2016;5:1290-6.

6. Wei F, Lin CC, Joon A, Feng Z, Troche G, Lira ME, et al. Noninvasive saliva-based EGFR gene mutation detection in patients with lung cancer. Am J Respir Crit Care Med 2014;190(10):1117-26.

7. Serhan CN. Systems approach to inflammation resolution: Identification of novel anti-inflammatory and pro-resolving mediators. J Thromb Haemost 2009;7 Suppl 1:44-8.

8. Rai G, Joshi N, Jung JE, Liu Y, Schultz L, Yasgar A, et al. Potent and selective inhibitors of human reticulocyte 12/15-lipoxygenase as antistroke therapies. J Med Chem 2014;57(10):4035-48.

9. Frankel DS, Meigs JB, Massaro JM, Wilson PW, O'Donnell CJ, D'Agostino RB, et al. Von willebrand factor, Type 2 diabetes mellitus, and risk of cardiovascular disease: The Framingham offspring study. Circulation 2008;118(24):2533-9.
10. Lee SH, Jeon YJ. Anti-diabetic effects of brown algae derived phlorotannins, marine polyphenols through diverse mechanisms. Fitoterapia 2013;86:129-36.

11. Gammone MA, Riccioni G, D'Orazio N. Marine carotenoids against oxidative stress: Effects on human health. Mar Drugs 2015;13(10):6226-46.

12. Yuan JP, Peng J, Yin K, Wang JH. Potential health-promoting effects of astaxanthin: A high-value carotenoid mostly from microalgae. Mol Nutr Food Res 2011;55(1):150-65.

13. Boussiba S. Carotenogenesis in the green alga Haematococcus pluvialis: Cellular physiology and stress response. Physiol Plantarum 2000;108:111-7.

14. Lorenz RT, Cysewski GR. Commercial potential for Haematococcus microalgae as a natural source of astaxanthin. Trends Biotechnol 2000;18(4):160-7.

15. Ursoniu S, Sahebkar A, Serban MC, Banach M. Lipid profile and glucose changes after supplementation with astaxanthin: A systematic review and meta-analysis of randomized controlled trials. Arch Med Sci 2015;11(2):253-66.

16. Yang Y, Kim B, Lee JY. Astaxanthin structure, metabolism, and health benefits. J Hum Nutr Food Sci 2013;1:1-11.

17. Stanier RY, Kunisawa R, Mandel M, Cohen-Bazire G. Purification and properties of unicellular blue-green algae (Order Chroococcales). Bacteriol Rev 1971;35(2):171-205.

18. Olaizola M. Commercial production of astaxanthin from Haematococcus pluvialis using 25,000-liter outdoor photobioreactors. J Appl Phycol 2000;12:499-506.

19. Liang H, Ma A, Zhang P, Bi SL, Shi DY. Effect of ethanol extract of alga Laurencia supplementation on DNA oxidation and alkylation damage in mice. Asia Pac J Clin Nutr 2007;16:164-8.

20. Milani E, Nikfar S, Khorasani R, Zamani MJ, Abdollahi M. Reduction of diabetes-induced oxidative stress by phosphodiestrase inhibitors in rats. Comp Biochem Physiol Part C Toxicol Pharmacol 2005;140:251-5.

21. Rajesh V, Perumal P, Sundarrajan T. Antidiabetic activity of methanolic extract of Smilax zeylanica Linn in streptozotocin induced diabetic rats. Internet J Endocrinol 2009;6:1-5.

22. Shalaby NM, Abd-Alla HI, Aly HF, Albalawy MA, Shaker KH, Bouajila J. Preliminary in vitro and in vivo evaluation of antidiabetic activity of Ducrosia anethifolia Boiss. and its linear furanocoumarins. Biomed Res Int 2014;2014:480545.

23. Dachicourt N, Bailbé D, Gangnerau MN, Serradas P, Ravel D, Portha B. Effect of gliclazide treatment on insulin secretion and beta-cell mass in non-insulin dependent diabetic Goto-Kakisaki rats. Eur J Pharmacol 1998;361(2-3):243-51.

24. El-Baz FK, Khalil WK, Booles HF, Aly HF, Ali GH. Dunaliella salina suppress oxidative stress, alterations in the expression of pro-apoptosis and inflammation related genes induced by STZ in diabetic rats. Int J Pharm Sci Rev Res 2016;38:219-26.

25. Valtonen P, Karppi J, Nyyssonen K, Valkonen VP, Halonen T, Punnonen K. Comparison of HPLC method and commercial ELISA assay for asymmetric dimethylarginine (ADMA) determination in human serum. J Chromatogr B 2005;828:97-102.

26. Fischer BE, Thomas KB, Dorner F. Von willebrand factor: Measuring its antigen or function? Correlation between the level of antigen, activity, and multimer size using various detection systems. Thromb Res 1998;91(1):39-43.

27. Hoffman P, Rauová D, Bezáková L, Obložinský M, Mikuš P. HPLC method for determination of lipoxygenase positional specific products. J Pharm Biomed Anal 2013;84:53-8.

28. Anthon GE, Barrett DM. Colorimetric method for the determination of lipoxygenase activity. J Agric Food Chem 2001;49(1):32-7.

29. Puchades Y, Ojalvo AG, García Y, Chinea G, Gerónimo H, Vispo NS. Identification of peptide mimics of the epitope recognized by CB-EGF1, a monoclona-lantibody EGF specific. Biotecnol Apl 2005;22:203-6.

30. Elsinghorst EA. Measurement of invasion by gentamicin resistance. Methods Enzymol 1994;236:405-20.

31. Drury RA, Wallington EA. Carleton's Histology Technique. $4^{\text {th }}$ ed. New York: Oxford University Press; 1980. p. 653-61.

32. Srinivasan S, Muruganathan U. Antidiabetic efficacy of citronellol, a citrus monoterpene by ameliorating the hepatic key enzymes of carbohydrate metabolism in streptozotocin-induced diabetic rats. Chem Biol Interact 2016;250:38-46.

33. Krzyzanowska K, Mittermayer F, Wolzt M, Schernthaner G. ADMA, cardiovascular disease and diabetes. Diabetes Res Clin Pract 2008;82 Suppl 2:S122-6.

34. Schnabel R, Blankenberg S, Lubos E, Lackner KJ, Rupprecht HJ, Espinola-Klein $\mathrm{C}$, et al. Asymmetric dimethylarginine and the risk of 
cardiovascular events and death in patients with coronary artery disease: Results from the AtheroGene Study. Circ Res 2005;97(5):e53-9.

35. Krzyzanowska K, Mittermayer F, Wolzt M, Schernthaner G. Asymmetric dimethylarginine predicts cardiovascular events in patients with Type 2 diabetes. Diabetes Care 2007;30:1834-9.

36. Lajer M, Tarnow L, Jorsal A, Teerlink T, Parving HH, Rossing P. Plasma concentration of asymmetric dimethylarginine (ADMA) predicts cardiovascular morbidity and mortality in Type 1 diabetic patients with diabetic nephropathy. Diabetes Care 2008;31(7):747-52

37. Dückelmann C, Mittermayer F, Haider DG, Altenberger J, Eichinger J, Wolzt M. Asymmetric dimethylarginine enhances cardiovascular risk prediction in patients with chronic heart failure. Arterioscler Thromb Vasc Biol 2007;27(9):2037-42.

38. Malecki MT, Undas A, Cyganek K, Mirkiewicz-Sieradzka B, Wolkow P, Osmenda $\mathrm{G}$, et al. Plasma asymmetric dimethyl arginine (ADMA) is associated with retinopathy in Type 2 diabetes. Diabetes Care 2007;30:2899-901

39. Ostergård T, Nyholm B, Hansen TK, Rasmussen LM, Ingerslev J, Sørensen KE, et al. Endothelial function and biochemical vascular markers in first-degree relatives of Type 2 diabetic patients: The effect of exercise training. Metabolism 2006;55(11):1508-15.

40. Natali A, Toschi E, Baldeweg S, Ciociaro D, Favilla S, Saccà L, et al. Clustering of insulin resistance with vascular dysfunction and lowgrade inflammation in type 2 diabetes. Diabetes 2006;55:1133-40.

41. Singla S, Singla S, Kumar A, Singla M. Role of epidermal growth factor in healing of diabetic foot ulcers. Indian J Surg 2012;74(6):451-5.

42. Das UN. Arachidonic acid and lipoxin A4 as possible endogenous anti-diabetic molecules. Prostaglandins Leukot Essent Fatty Acids 2013;88(3):201-10.

43. Naito Y, Uchiyama K, Aoi W, Hasegawa G, Nakamura N, Yoshida N, et al. Prevention of diabetic nephropathy by treatment with astaxanthin in diabetic $\mathrm{db} / \mathrm{db}$ mice. Biofactors 2004;20(1):49-59.

44. Kurashige M, Okimasu E, Inoue M, Utsumi K. Inhibition of oxidative injury of biological membranes by astaxanthin. Physiol Chem Phys Med NMR 1990;22(1):27-38

45. Jewell C, O'Brien NM. Effect of dietary supplementation with carotenoids on xenobiotic metabolizing enzymes in the liver, lung, kidney and small intestine of the rat. Br J Nutr 1999;81(3):235-42. 